\title{
The appearance of accountability: communication technologies and power asymmetries in humanitarian aid and disaster recovery
}

\author{
Mirca Madianou \\ Goldsmiths - University of London \\ Jonathan Corpus Ong \\ University of Leicester \\ Liezel Longboan \\ Independent researcher \\ Jayeel Cornelio \\ Ateneo de Manila University
}

Article published in: Journal of Communication (2016)

\begin{abstract}
New communication technologies are celebrated for their potential to improve the accountability of humanitarian agencies. The response to Typhoon Haiyan in 2013 represents the most systematic implementation of 'accountability to affected people' initiatives. Drawing on a yearlong ethnography of the Haiyan recovery and 139 interviews with humanitarian workers and affected people, the article reveals a narrow interpretation of accountability as feedback which is increasingly captured through mobile phones. We observe that the digitized collection of feedback is not fed back to disaster-affected communities, but is directed to donors as evidence of 'impact'. Rather than improving accountability to affected people, digitized feedback mechanisms sustained humanitarianism's power asymmetries.
\end{abstract}

Keywords: accountability, audit, communication for development, participatory communication, ICT4D, disasters, humanitarianism, mobile phones, texting, SMS, ethnography.

Corresponding author: Dr. Mirca Madianou (m.madianou@gold.ac.uk), Department of Media and Communications, Goldsmiths - University of London, New Cross, London, SE14 $6 \mathrm{NW}, \mathrm{UK}$

Acknowledgement: the research reported in this article was funded by the UK's Economic and Social Research Council (ESRC) (ES/M001288/1) 


\section{The appearance of accountability: communication technologies and power asymmetries in humanitarian aid and disaster recovery}

This article brings together two key developments in contemporary humanitarianism: the increasing emphasis on processes of accountability and the optimism surrounding the adoption of the internet and mobile phones for achieving this purpose. Accountability has been key to humanitarian reform, which emerged as a response to earlier critiques of humanitarianism. Making aid agencies accountable to the different stakeholders, including the affected people whom they aim to serve, requires transparency and the involvement of beneficiaries in the planning, implementation, monitoring and evaluation of relief programmes. It is not surprising then that recent developments in interactive communication technologies such as social media and mobile phones have been met with enthusiasm by representatives of humanitarian organizations. Digital technologies have been praised for the capacity give voice to affected people and hold humanitarian agencies into account thus addressing the power imbalances in the responder-beneficiary relationship. The term 'Humanitarian Technologies' used by organizations such as the Red Cross in their World Disasters Report (WDR, 2013) to refer to the uses of interactive technologies by disaster affected people reveals the optimism surrounding technology in the humanitarian field.

Yet, despite this recent optimism there is little evidence to support the above claims. This article investigates the uses of digital communication technologies for accountability purposes in the context of the recovery from Typhoon Haiyan (locally known as Yolanda) that hit the Philippines in November 2013 triggering a major humanitarian response. The response to Typhoon Haiyan was widely regarded as the most systematic implementation of accountability 
initiatives by humanitarian agencies (Jacobs, 2015a). The high levels of mobile phone and social media use in the Philippines were quickly recognized as opportunities to improve accountability structures (Jacobs, 2015a, p. 15). Our research, as part of a larger ethnography on the uses of communication technologies in the Haiyan recovery, explores this link. Drawing on interviews with representatives of humanitarian organizations, especially accountability officers involved in the Haiyan recovery, as well as interviews and participant observation with affected people, our research reveals that agencies have adopted a narrow definition of accountability as 'feedback' by affected people. We argue that although new communication technologies increase and intensify the methods for collecting feedback, they do not necessarily improve accountability to affected people. Crucially, accountability mechanisms are more often directed to stakeholders and funders who require evidence of 'impact'. In this way, communication technologies and the new feedback processes they enable do not correct the power asymmetries of humanitarianism and can even have negative consequences if not responded to by the agencies. The next section traces the emergence of accountability in the humanitarian field followed by a discussion on the qualities of new communication technologies in the context of humanitarian practice.

\section{Humanitarian aid and accountability}

The story of humanitarian reform is often told as the response to the deficiencies of humanitarian action and the failure to mitigate specific crises, most notably the Rwandan genocide (Terry, 2002). Such criticisms added to pre-existing critiques about the power asymmetries on which humanitarian relief is based and the acknowledgment that humanitarian aid may even have unintended negative effects including the disruption of local societies and social solidarity and the perpetuation of a culture of dependency (de Waal, 1997). Despite the 
noble intentions of agencies and aid workers humanitarianism has been likened to a form of neocolonialism and imperialism (Rieff, 2002) while its negative consequences are compounded by the lack of accountability within the field (Davis, 2007, p. 1). According to the Oxford English Dictionary, accountability broadly refers to 'the obligation or willingness to accept responsibility for one's actions and their consequences'. A number of reform initiatives aiming to improve the accountability of humanitarian agencies were introduced in the 1990s as a response to the above critiques. The two most prominent initiatives were the Sphere Project and, later, the Humanitarian Accountability Partnership (HAP). These initiatives merged into the Core Humanitarian Standard (CHS) in 2014 and converged with parallel efforts within the sector to strengthen the participation of affected communities in humanitarian operations through Communication with Communities $(\mathrm{CwC})$ initiatives.

Although the Rwanda crisis provided the impetus for the Sphere project (BuchananSmith, 2003) the demand for humanitarian accountability didn't just emerge as a response to humanitarianism's limitations. It was also the result of its success. In 2010 there were an estimated 274,000 humanitarian workers while by 2012 there were over 4,400 non-governmental organizations (NGOs) worldwide with a budget of over US\$16 billion (Taylor, Stoddard, Harmer, Haver \& Harvey, 2012, p. 9). By 2014 the relief aid economy globally had risen tenfold since 2000 to reach US\$156 billion (IRIN, 2015). Humanitarianism has been affected by wider processes such as globalization and neoliberalism. The growth of the sector is largely explained by a structural shift whereby states have withdrawn from the provision of aid which they now outsource to humanitarian agencies (Stein, 2008). Yet states remain involved as the main funders and regulators for humanitarian agencies. Donors demand that agencies demonstrate that their projects have had the intended consequences. The pressure for 'outcomes' and 'impact' is also 
driven by these structural changes in the field of humanitarianism. There are clear parallels here with other sectors of professional life, such as education, which has also experienced an explosion of audit (O’Neill, 2002; Power, 1997; Strathern, 2000).

Krause has compellingly described how the humanitarian field operates as a quasi market in which agencies compete for donor funding and in which beneficiaries are not simply the end of humanitarian relief but also 'the means to an end' (Krause, 2014, p. 40). Populations in need essentially legitimate humanitarian projects and justify agencies' funding applications to institutional donors. Krause's critical analysis of the instrumental relationship between agencies and affected people thus draws our attention to the gathering and delivery of evidence that justify agency interventions. Our paper investigates the role of technology as mediating the relationship between agencies, beneficiaries and donors.

This analysis of the political economy of humanitarianism is essential for understanding the emergence of accountability as part of recent humanitarian reform initiatives. We discern two types of accountability, namely accountability to affected people and accountability to donors. Accountability to affected people emphasizes agencies' obligations vis a vis communities' rights to a dignified life; accountability to donors is concerned primarily with a process of auditing and evaluation of outcomes. While accountability to affected people is concerned with the ethics of the humanitarian/beneficiary relationship, accountability to donors is a technical matter of outcome evaluation. Although the intentions of humanitarian reformers are idealist and aimed to serving beneficiaries, Krause (2014) suggests that the two major reform initiatives of the last 20 years (namely, Sphere and HAP) are ultimately geared towards donors- just as reports from within the sector recognize that 'upwards accountability' "squeeze[d] out" accountability to affected populations' (Steering Committee for Humanitarian Response [SCHR], 2010, p. 6). ${ }^{1}$ 
Critique has also been strong from humanitarians who work within the Sphere and HAP

parameters. A report commissioned by HAP in 2013 reveals that:

... there has been a tendency to deal with accountability in increasingly technocratic, depoliticized and self-referential terms by humanitarian organizations. Put in another way, there has been a shift in focus from macro- to micro-accountability. (Darcy, Alexander \& Kiani, 2013, p. 5)

The response to Typhoon Haiyan launched a new reform initiative, Accountability to Affected People (henceforth, AAP), which synthesizes Sphere and HAP. Despite the emphasis on beneficiary participation and communication with communities in AAP initiatives, AAP was criticized from within the sector. For example, the Haiyan inter-agency coordinator noted that the 'attraction to functional and structured language of tools and mechanisms has been accompanied by a drift away from the primary purpose of a culture of accountability' (Wigley, 2015 , p. 14). Also acknowledged are the systemic obstacles to realizing the goals of accountability rhetoric in actual practice: 'agencies often have to focus on hastily determined goals about "spend rates" and "output delivery," rather than listening and responding to people's changing needs (Jacobs, 2015b). The sometimes passionate debates on accountability among humanitarians reveal that what is truly at stake here are 'humanitarian ethics and humanitarian identity' (Stein, 2008, p. 125) - in other words accountability touches on the essence of humanitarian practice.

\section{Accountability as a problem of communication: parallels with participatory development}

The critique of humanitarian accountability echoes debates about participatory development. There are many similarities: AAP depends on grassroots participation while the latter is strengthened through structures of accountability. Accountability was a concern in 
development before it emerged in the agenda of humanitarianism which was traditionally preoccupied with saving lives. The demand for accountability has increased as the developmenthumanitarian relief boundaries become porous: development agencies compete for humanitarian funding while humanitarian agencies become engaged in development work following the initial emergency phase (Krause, 2014). Crucially, both accountability and participation depend on dynamic, horizontal communication with and within local communities and both have been intended as correctives to power imbalances in humanitarianism and development (Wilkins, 2000).

Participatory development was radical in its inception by foregrounding the engagement of local people in the process of change. This involves recognizing the value of local knowledge and involving people in determining the problems, identifying the solutions, making decisions and implementing initiatives (Manyozo, 2012). Rather than a top down mechanism for information dissemination, communication is the tool for empowering local communities to find a voice, effect change and take control of their own futures. Yet the development system has been criticized for co-opting participation and turning it into a set of technocratic, measurable goals. According to some critics the institutionalization of participation has turned it into a simple rhetoric in the service of neoliberalism (Cooke and Kothari, 2001; Leal, 2007). Waisbord (2008) developed a nuanced critique of the institutional reasons why participatory communication remains limited. According to his account, one of the main obstacles to true participation is the aid bureaucracy which favours informational, top down models which allow greater control of outcomes, rather than bottom up, messier, participatory models (Waisbord, 2008, p. 511-13). Similar arguments, coupled with the structure of humanitarian funding outlined in the previous section, can also explain the limits of accountability. Like participation, 
accountability to affected people depends on dynamic communication between agencies and local people. Accountability can be thus understood as a problem of communication that mediates asymmetrical power relationships. Interestingly, in the humanitarian field communication initiatives are increasingly technologically mediated. Given the increasing prominence of communication technology in AAP initiatives our paper puts forward an analytical framework about communication technology for humanitarian accountability, which has been so far neglected in the literature.

\section{Humanitarian accountability and mobile media}

Given the prominence of accountability in current debates on humanitarian practice it is not surprising that developments in communication technologies, and in particular mobile phones, have been welcomed as opportunities to improve humanitarian action. Mobile phones are growing faster in the developing world than anywhere else and are widely regarded as tools for development (Ling and Donner, 2009; World Bank, 2012). The popularity and interactive nature of mobile media are seen as opportunities for affected people to make their voices heard and hold humanitarian agencies into account. It is for this reason that mobile media were widely employed in the AAP initiatives during the Haiyan recovery. Although in other publications we observe that several affected people had access to a broader communications landscape (Madianou, Longboan \& Ong, 2015), mobile media and in particular the platform of short messaging service (SMS, or else texting) were prioritized in AAP initiatives. SMS lowers the barrier of participation among disadvantaged communities who are the primary recipients of relief. Most humanitarian agencies in the Haiyan response launched SMS 'hotlines' using open source software such as FrontlineSMS which enables users to send texts to a designated number 
at low cost. FrontlineSMS in turn aggregates these short messages into databases thus facilitating the processing of feedback. Our analysis takes into account this convergence between feature mobile phones, open access software and wider communications environments although the emphasis will be on mobile media given their prominence in AAP initiatives. The article compares the aid agencies' communication technology initiatives with their actual uses by disaster affected people.

This section unpacks the features of interactive platforms and in particular mobile phones in order to understand their intersection with humanitarian reform initiatives. Our approach is broadly informed by the social shaping of technology paradigm (MacKenzie \& Wajcman, 1999) as well as ethnographic understandings of communication technologies (boyd, 2014; Madianou \& Miller, 2012). We recognize that technologies have specific qualities which facilitate some types of interaction and not others (Baym, 2015). Affordances are not determining, but they do contribute to the kind of communication that is possible in digital environments. Our ethnographic perspective allows us to trace the way in which these affordances are appropriated by users in the context of their everyday practices (Madianou \& Miller, 2012). We are here interested in the actual uses of technology by humanitarians and affected people rather than the focus on 'big data' for the co-ordination of relief (Crawford \& Finn, 2015), or on digital volunteerism which are separate topics (Palen, 2008).

It is assumed that the interactivity of mobile phones translates into increased participation and accountability. Users can now generate and share content as well as interact with other individuals and groups on a scale that was impractical with traditional mass media. Apart from horizontal communication among peers, vertical communication (between beneficiaries and humanitarians) can potentially 'lead to community empowerment' by giving voice to affected 
people (WDR, 2013, p. 58) and even correct the asymmetries of humanitarianism - a concern which is at the heart of reform initiatives such as HAP. Rather than assuming the consequence of this particular affordance, our research asks to what extent do affordances translate into actual participation? The other feature of mobile media that has been central to accountability initiatives, is the SMS functionality which allows users to send short messages of up to 160 characters. SMS messages are digitally recorded and thus traceable and retrievable by those who receive them. Texting's content permanence means that the SMS sent by affected people can be easily indexed and aggregated, especially when facilitated by software such as FrontlineSMS. Further, communication through mobile phones can potentially widen the agencies' reach, as it can include people in remote areas who are unable to travel to post their comments in suggestion boxes or attend community consultations.

The character restriction of texts can have implications for what is communicated in SMS. Despite the development of special language that includes abbreviations and emoticons in order to enrich meaning and add social cues (Baron, 2010; Pertierra, Ugarte, Pingol \& Decanay, 2002) the 160 character limit of SMS has been found to be more effective for activities such as coordination rather than deliberation (Castells, Fernandez-Ardevol, Qiu \& Sey, 2006). This contrasts with the affordances of Web 2.0 platforms such as social network sites where users can potentially have a dialogue around social issues, or at least explain their concerns at length and with the help of visuals. Comparing SMS with social network sites we identify several differences which crystallize some of the potential limitations of texting. Texting is essentially a form of asynchronous communication between two interlocutors. Sending a complaint to a humanitarian agency will not share the message with one's peers. This can be great from a point of view of privacy, but it will not generate any public discussion or deliberation around problems 
faced by communities as a whole which is enabled in face-to-face community consultations, or on social network sites as we will see below. Recent research points out that people are likely to choose from a range of media platforms depending on their audience and communication intentions. This suggests that rather than focusing on distinct platforms we need to understand communication technologies as environments of communicative opportunities which users navigate in order to meet their needs (Madianou \& Miller, 2012). For example, a user can send a text to complain to an agency followed by posts in social media in order to collectively discuss the recovery. Understanding communication media as environments contrasts with the agency practice that prioritizes one platform, namely SMS. Our analysis will compare the SMS initiatives with their actual take up, but we will also be attentive to practices within people's wider communication environments.

The question of digital inequality underlies this discussion. Although mobile teledensity in the Philippines exceeds $100 \%$ and the country is celebrated as being at the forefront of mobile phone and social media developments (GSMA, 2014) such figures conceal internal variations. A survey found that only 83 percent of Taclobanons had access to a mobile phone following the Typhoon which confirms our data (Hartman, Rhoades \& Santo, 2014, p. 14). Those without phones were typically the poorest participants and therefore those most likely to require relief. Moreover, apart from those with no access to a mobile phone our sample also included a large group of participants (42 out of 101 participants) with a very diminished media landscape, no internet access and no digital skills (Madianou, 2015).

\section{Empirical context and methods}


Typhoon Haiyan, which hit the Visayas region of the Philippines on November 82013 , remains the strongest typhoon to make landfall triggering a massive humanitarian response in its wake. Conservative estimates put the death toll at well over 6,300 while more than 12 million people were affected many of whom displaced (National Economic and Development Authority, 2014). With funding from an ESRC grant we conducted an ethnography of two sites affected by Haiyan in order to understand the role of communication technologies in the recovery context. The paper reports on this multi-sited ethnography in the city of Tacloban (in Leyte) and the island of Sabay ${ }^{2}$ between April 2014 and January 2015. Tacloban, the administrative capital of the Eastern Visayas region, suffered the worst devastation in terms of casualties and damage to infrastructure as five-meter waves hit its shorelines. Tacloban became the focus of relief operations run by dozens of agencies. In contrast, Sabay is a small island in the Visayas dependent on fishing and some tourism, which suffered substantial physical damage but few casualties. The article draws on data from both locations but it is not our aim here to develop a comparison of the two fieldsites.

During our 10-month ethnography we conducted participant observation and interviews with 101 participants affected by the typhoon (several of whom were interviewed more than once). Ethnography is acknowledged as a suitable method when undertaking research with disaster-affected people (Adams, 2013). We met our participants through our ethnography of selected barangays (neighbourhoods) in the two fieldsites. Participants came from a broad range of backgrounds, ages and socio-economic classes: our sample included 55 women and 46 men; 63 of our participants were very low, or low income, while 38 were middle class. All our participants were affected by the typhoon, but the majority of low-income participants lived in temporary accommodation even one year from the disaster (see Madianou, 2015, for an account 
of the delayed and uneven recovery). Interviews lasted 90 minutes on average and were recorded, transcribed, anonymized ${ }^{3}$, coded and analyzed thematically. Apart from our interviewees we met several other participants as part of our ethnographic encounter which immersed us in the everyday lives of our participants and involved sharing meals, attending barangay fiestas, church services, funeral wakes, community consultations and protest marches. Our data include our extensive fieldwork notes. The study also includes additional interviews with 38 experts (mainly representatives from humanitarian organizations, but also other local civil society groups and government agencies). Our sample consisted of the well-established humanitarian organizations as well as smaller agencies while we interviewed officers at different levels within the organizational hierarchy (field staff, accountability officers and representatives from national offices or headquarters). The expert interviews followed the same protocol as with affected people but with a different interview guide which focused on the agency projects and initiatives in the affected areas. As part of our ethnography we visited agency offices and attended consultations. Notes from these encounters have also informed the analysis.

Our research is unique for bringing together the perspective of affected people and humanitarian workers - most existing projects focus only on one. Combining both perspectives, as we do in the following sections, allows us to compare the accounts of accountability officers at different levels of the organizational hierarchy with the experiences of crisis-affected people in order to gain a holistic understanding of accountability initiatives and the role of communications technology in that process.

\section{Accountability as feedback in the Haiyan recovery}


The response to Typhoon Haiyan represents the most systematic implementation of accountability initiatives by humanitarian agencies. Because of the existing technological infrastructure in the Philippines, Haiyan was widely seen as the ideal laboratory to pilot 'accountability to affected people' (AAP) and 'communicating with communities' (CwC) initiatives. Most agencies employed accountability officers while it was common for the larger agencies to employ AAP and $\mathrm{CwC}$ teams as large as 14 people. Haiyan was also the first time that an AAP inter-agency coordinator was deployed (Wigley, 2015).

What was striking in the Haiyan response was the narrow translation of accountability as feedback. Of all the possible ways in which accountability can be defined and implemented, humanitarian agencies chose to focus on feedback, in line with earlier initiatives such as HAP (Krause, 2014). The second important observation is that of all possible feedback collection methods, digital platforms and particularly SMS hotlines were prioritized as the key channel. Although international agencies had several feedback mechanisms at their disposal including face-to-face consultations, suggestion boxes and help-desks, feedback obtained through SMS was more likely to be included into the agency feedback logs. Our humanitarian respondents explained the limitations of traditional channels. For example, one officer acknowledged that accountability teams struggled to capture feedback offered in one-to-one conversations between affected people and field staff. This is because field staff, who are tasked to implement programmes and who are in regular contact with affected people, are not formally responsible for cataloguing feedback. Even if they come across complaints, it is not considered their job to relay these criticisms to the accountability team. Field staff welcomed SMS feedback mechanisms and referred dissatisfied beneficiaries to those hotlines. Though affected communities sometimes interpreted these referrals to formal feedback mechanisms as agency workers shooing them 
away, from the agency workers' point of view the tangible form of SMS feedback formalized complaints or concerns thus adding them weight. Still, it is a worrying development if technological mechanisms and their affordances for easy cataloguing of feedback are used as justifications by agency workers to be less immersed with affected communities. As such, aid agency feedback databases usually reported higher numbers of complaints or comments gathered from technologically mediated mechanisms than face-to-face conversations. For instance, World Vision's database listed over 3000 feedback entries from suggestion boxes and SMS compared to only around 700 from help desks and community consultations over a period of one year (Buchanan-Smith, Ong \& Routley, 2015). These figures contrast with the observation that local people expressed preference for face-to-face communication compared to technologically mediated platforms when discussing complaints, something many of our humanitarian interviewees were aware of (CDAC, 2015; Hartman, Rhoades \& Santo, 2015). The prioritization of digitized feedback is illustrated by the experience of one accountability officers who told us that 'the first thing she was asked to do as an absolute priority' as soon as she arrived in the field was to set up the agency's SMS hotline. Our respondent did so only to realize weeks later that this was the least useful tool for gauging the thoughts of the communities she was working with.

Feedback mechanisms can have a distorting effect on accountability processes, where feedback gathered through technological means is more likely to be counted compared to feedback expressed in other settings, especially face-to-face contexts. Digitized feedback excludes those without access to a mobile phone. Even though this is a small proportion of the general population, it is likely to include the poorest people who are usually those who are most adversely affected by disasters (Madianou, 2015). A second distortion concerns the type of feedback that is received and validated. It is questionable whether complex problems and 
concerns such as those faced by our participants can be conveyed in 160 characters, which raises questions about the representativeness of feedback collected.

This is evident in the case of several of our participants who did not use agencies' formal feedback mechanisms and instead found other avenues to express their complex complaints about the recovery. Lorna, a young mother from Tacloban who lost her husband in the typhoon, complained to national media about the agencies' beneficiary selection criteria - a very public expression of grievance, which she hoped would draw attention to her case. Her complaint was not acted upon, as it did not register in the agency feedback databases that accountability officers are tasked to monitor. This highlights a further distortion: only feedback submitted via the designated channels counts as feedback. Feedback relayed in informal channels (such as broadcast media or social network sites) is not recorded, digitized and tracked and does not carry the expectation to 'close the feedback loop'. However, given the proliferation of media platforms feedback is increasingly likely to be found outside the formal mechanisms, for example, in social network sites where some of our participants engaged in discussions about the slow nature of recovery. Moreover, NGO feedback excludes comments captured through the national government's own feedback mechanisms. Five of our participants used these platforms, often to complain about the politics of aid distribution which was largely implemented via local government structures thus reproducing existing patronage relationships. ${ }^{4}$ This illustrates that feedback cannot be neatly disaggregated into government or aid agency related, although these are treated separately.

The final crucial distortion created by agencies' audit mechanisms is that they typically invite feedback in relation to specific interventions. In other words, feedback counts if it addresses existing relief programmes and not wider issues or concerns about 
the recovery. For example, during Haiyan, aid distribution was selective focusing on specific sectors or individuals who were deemed particularly needy. Only those who received aid were expected to submit feedback. Unsurprisingly, those excluded from aid or livelihood programmes often harboured strong feelings about their exclusion and the recovery as a whole. In the island of Sabay, for example, while fishermen were the focus of many livelihood programmes, other sectors (such as pedicab drivers) were not included in similar initiatives. Yet, the feedback of those excluded from the relief efforts is not captured through the formal feedback mechanisms - their complaints simply don't count as feedback. Accountability officers in turn, are only expected to respond to feedback that pertains to the delivery of existing and specific programmes so they hardly ever act on feedback given on issues beyond their existing remit, as we discuss in a later section.

\section{Feedback in the Filipino Context}

A striking set of images from our fieldsites were the so-called 'thank you shrines' built by affected people as testaments to their gratitude to aid agencies. These 'shrines' made out of pebbles and seashells usually forming the phrase 'thank you' were found on the side of busy streets or roundabouts and materially inscribed gratitude into the physical environment. Agency workers whom we interviewed shared their observation that local people are not used to expressing complaints. Frank, an accountability officer, said that they had to use the term 'feedback' and not 'complaint' when advertising their mechanisms. In his agency, he claims that 90 percent of the feedback messages were 'thank you' notes from beneficiaries grateful for the aid they have received. Indeed, we visited agency offices where the numerous 'thank you' notes posted through suggestion 
boxes were used to decorate bulletin boards. We were also able to obtain some feedback databases from some of the agencies and our analysis confirmed Frank's assessment about the popularity of 'thank you' messages. Here's an example of a typical 'thank you' SMS:

Good evening all I can say about the help you gave us is THANK YOU SO $\mathrm{MUCH}$ to all of you wish you can continue to help us, may GOD repay you for your assistance.

These expressions of gratitude exist in parallel with feelings of resentment and anger held by many people in affected areas, as many people have struggled to endure the loss of shelter, livelihood, and even their loved ones. Some respondents complained to us about the indignities they suffered during disorganized relief good distributions. Many people were very critical of agencies' selection criteria, especially toward the traditional agency practice of targeting those deemed to be most deserving in the community while excluding others. Some participants felt that the criteria for the selection of beneficiaries were unclear and often determined by pre-existing relationships of patronage (recall that relief was filtered through local government structures). The inequalities caused by agencies' selective aid distribution triggered status anxiety within tight-knit communities with a tradition of mutual aid and cooperation when recovering from crises, causing people like Rowena to complain, 'neighbours and friends have become enemies because of these NGOs' criteria' (see also Ong, Flores \& Combinido, 2015). Interestingly, such comments were made to us in the context of our ethnography but they were not formally expressed as 'feedback' to agencies.

So what explains the reluctance to formalize negative feedback? And what explains the predominance of 'thank you' messages over complaints in the official agency logs? Anthropological work on the Philippines has stressed the significance of utang na 
loob, or debt of gratitude, as a key moral norm that shapes social relations. People owe a debt of gratitude to those who extended them assistance, especially those who have gone beyond normal expectations of kin relationships (Rafael, 1995). This is compounded by long histories of patronage politics especially at the local level, where asymmetrical power relationships based on debt of gratitude bind poor people to local leaders who offer them charity and protection (Lau \& Cornelio, 2015). In the context of Haiyan, people feel 'obliged to be grateful' to agency workers (Ong, Flores \& Combinido, 2015), as they are recognized as helping them without expecting anything in return, hence the barrage of 'thank you' notes in humanitarian offices. Additionally, we also found evidence of silencing resulting from fears about the withdrawal of aid, as well as more subtle forms of silencing due to lack of self-confidence and feelings of helplessness, as people internalize views that their low socio-economic status diminishes the value of their participation (Madianou, Longboan \& Ong, 2015). All this suggests that the concept and practice of humanitarian accountability within the Philippine context are constrained by cultural and socio-political factors which have not been taken into to account by aid agencies. At a broader level we argue that the concept of accountability and feedback reflects the values of the agencies' own cultures and does not resonate with local norms in disaster-affected areas.

By contrast, our participants were more likely to direct their negative complaints to the national or local governments. We often came across expressions of deep frustration towards the government and its handling of the recovery. One interpretation for this discrepancy might be the long standing criticism of corruption and cronyism associated with national politics: Haiyan wasn't the first occasion when our participants were let 
down. We also came across the view that local leaders were indebted to Filipino people who had elected them with their votes. There may also be an element of colonial legacy here as our participants were less critical to what they perceived as 'powerful outsiders'.

\section{Who participates - and with what outcomes?}

The particular norms of debt of gratitude and the wider sociopolitical context of the Philippines explain why only 9 out of our 101 participants used the various feedback platforms made available by the aid agencies. Although this is a small sample, the figure is corroborated by our 10-month ethnography during which we informally met dozens more participants very few of whom had used the agency feedback mechanisms. So who are those who participate in the formal feedback mechanisms described above? SMS hotlines exclude those without mobile phones which made up 10 per cent of our sample and typically were the poorest participants. Here we will briefly contrast two portraits of participants who gave feedback using the SMS feedback platform and whose stories are representative of those who used SMS hotlines.

Gloria from Tacloban was denied farming assistance by an aid agency because her son is an overseas Filipino worker (OFW) in the Middle East. Although she met all criteria to receive benefits, Gloria was told that families with OFW members were excluded from the list, as agencies assumed they are less needy. But while gossiping with her neighbours, she discovered the selection criteria had been inconsistently applied and her neighbours had received benefits. Feeling aggrieved and -we suspect- jealous by these discoveries, Gloria appealed twice to be included. When her request was denied, she used the agency SMS hotline to name and 'squeal' on her neighbour who received assistance despite not meeting the criteria. Gloria’s squealing led 
to the agency revalidating the beneficiary list and excluding her neighbour from future distributions. Gloria justified to us that she 'helped correct distribution lists', though it is evident from our participant observation that neighbour relations were strained following this incident.

Dolores is a stay-at-home mother to two children and married to a trisikad (nonmotorized tricycle) driver. Dolores’ husband earns Php100/day (US\$2.25). Her barangay was among the poorest that we saw on the village, and yet Dolores' house looked exceptionally destitute even compared with her neighbours. While her neighbours had new iron roofs donated by agencies, her house was sheathed with an old tarpaulin as a makeshift roof, which leaked during rainy days. Dolores was frustrated with the way aid agencies in Sabay have focused on fishermen as beneficiaries, excluding most of those in the transport sector. The island, wellknown as a fishing community, received several targeted interventions to fisherfolk to the almost total exclusion of trisikad drivers. Dolores recounted to us how she sent an SMS to request for livelihood assistance. She only received an automated acknowledgment from the agency with no follow-up response. Four months after she had sent the text, she told us how she still hoped that the agency would come and visit her so she could actually explain to them how she had to resort to borrowing money from relatives, friends and lending agencies to sustain her family and repair their household. She still hoped for an opportunity to express the suffering that she hadn't been able to convey in a bare-bones SMS of 160 characters: 'My name is Dolores. Please also help the trisikad drivers. I live in barangay x'. Dolores' experience of just receiving an automated acknowledgement is typical of half of those in our sample who used the formal feedback mechanisms.

It is striking that the poorest of all our participants who used SMS feedback was the one who failed to get a response. The key difference here is that agencies acted on Gloria's feedback 
as her issue directly related to an existing intervention. Still even Gloria's example reveals one of the distortions of SMS as it facilitated 'squealing' but not her original complex issue of exclusion from aid. But in Dolores' case, her feedback requested attention to a household not included in any existing intervention - it simply didn't count as feedback. This is an example of how humanitarian accountability is narrowly translated as at best tweaking the delivery of existing programmes rather than a radical rethinking of relief policies as a result of grassroots communication. ${ }^{5}$ The aim of using SMS technology to empower local people to hold agencies into account wasn't realized for Dolores and the other participants who didn't receive a response from the agencies. Arguably, even Gloria's example is not empowering as it reveals the limitations of texting. In both Gloria and Dolores's cases the 160 characters of SMS were not able to convey the life context or predicament affected people, reducing appeals down to their barest, instrumental forms. Squeals or requests conveyed via SMS can be interpreted as interpersonal jealousies within affected communities if decontextualized from Filipino village cultures and the divisiveness caused by unequal distributions. These two examples suggest that SMS feedback does not equal grassroots participation. Because of the narrow definitions of feedback, participating in SMS mechanisms does not guarantee that one will be listened to. Moreover, the affordances of SMS compound the distortions in the feedback process and reduce complex problems to instrumental squeals.

\section{(Not) closing the feedback loop}

Dolores' story is a case where the 'feedback loop' was not closed. Among agencies' key measures of accountability is 'closing the feedback loop', which includes the following steps: sending an acknowledgment that feedback has been received, analyzing feedback and 
communicating this with relevant parties, designing a response, and communicating the actions taken (or not taken) to the community or affected person (Jean, 2013, p. 8). Humanitarians themselves anticipate that not getting a response likely results in 'distrust and lack of engagement' among communities (Hartman, Rhoades \& Santo, 2014, p. 23). Although not all agencies had well-resourced accountability projects, accountability officers whom we interviewed acknowledged the importance of recognizing beneficiaries' concerns. Agency workers recognized that sending an acknowledgment conveys respect for the affected person and at the same time manages expectations. Indeed, acknowledgment is at once an expression of sympathy and an effort to professionalize agencies' relationships with their beneficiaries through the language of consumer transaction.

Despite the best intentions, feedback loops were often not closed. Of our nine respondents who used the NGO feedback mechanisms, only three received small corrections to their problems - as in the case of Gloria. These small tweaks, do not respond to calls for new programme interventions, as this is beyond the remit of accountability officers. The tweaks are usually small adjustments to beneficiary lists which can be well-received by those concerned although they can also rupture community solidarity. This was the best outcome our participants could hope for after submitting their feedback.

Four of our participants only received an acknowledgement that their message had been received without any further follow up while two of our participants didn't even receive that. Those who didn't receive an outcome or even an acknowledgment told us they were unlikely to provide feedback again - they felt demoralized. In the case of Dolores, her exclusion from aid and the agency's lack of response amplified her already existing desperation which was evident when we first visited her house and Dolores assumed we were representing the NGO finally 
responding to her SMS. Dolores became resentful of her exclusion and ashamed of her position of being left-behind by her neighbours with their new iron roofs and vegetable gardens, especially given the Filipino village context where neighbours are considered as extended family (McKay, 2012). Unsurprisingly, Dolores said that she would never use feedback mechanisms again in the future, confirming disengagement as a likely outcome when not closing the feedback loop. If digitized feedback is the instrument to strengthen accountability to affected people and democratize humanitarianism, it here fails to fulfill this promise. 'Not closing the feedback loop' coupled with the narrow definition of what counts as feedback and low participation of our respondents in formal feedback mechanisms reveal a profound disconnect between affected people and humanitarian agencies. If feedback mechanisms are not improving accountability to affected people, then who are they for?

\section{Accountability to whom?}

Curiously, accountability officers themselves did not experience feedback loops being closed, insofar as the feedback loop should involve agency workers being properly informed about how their analysis of feedback has led to strategic program development. One accountability officer responsible for producing monthly reports for the national office told us: 'Once I submit the report to the national [level], I have no idea what they do with it... I have no idea whether this new program that we're implementing was a result of my suggestion from a few months ago'. Although AAP became prominent during the Haiyan response, officers nonetheless told us that decision-making was rarely driven by the accountability team. In fact some of the accountability officers we met considered their move to project management roles as a promotion insofar as they found more decision-making powers in their new role. Workers on 
the ground, who are usually most aware of the needs of affected people and the nuances of the recovery, have little power to decide programmes and shape policies.

Our visits to the local headquarters of a large agency further illustrate these points and reveal the audience for these audit exercises. In that agency the accountability team of four staff were painstakingly translating the feedback messages from the local dialect into Tagalog and then into English. The entries were subsequently anonymized, coded and entered into a spreadsheet. Feedback datasets were prepared for the head office in Manila which, as the officers told us, will ultimately forward it to the agency's headquarters in Europe to be used in reports for new funding applications. The dataset with its listing of SMSs received provides tangible evidence for the work of the agency in the affected area. An officer from a neighbouring agency also confirmed that "we provide [the head office] a summary of the feedback recorded in the database every week'. As another accountability officer explained:

The cellphone technology has made things much, much easier. And I guess it made things much more accountable within organizations because you can't hide from providing the information by sending reports. You just can't be on your own little bubble doing whatever. You have to be accountable to the head office. You know donors demand a report every two months, and you know it's not something you have to type on a typewriter anymore, trying to fax or hand-carry to Manila and send from there. We're no longer relying on carrier pigeons. But you know, the cellphone has made us more accountable because we are now expected to provide updated information about the work that we are doing $[\ldots]$ we can send the [feedback] database.

These examples reveal that one of the major tasks of accountability teams was the production of a weekly or monthly report and spreadsheet for the head office while the team did not receive follow ups from the national office about the actions resulting from their reports. According to our interviewees SMS rarely trigger a meaningful programme review which would constitute evidence of actually listening to affected people thus recognizing their ability to influence agency practices, reverse power asymmetries and 'participate in disaster recovery' as is Madianou, M., Ong, J., Longboan, L. and Cornelio, J. (2016) The appearance of accountability: communication technologies and power asymmetries in humanitarian aid and disaster recovery. Journal of Communication vol, 66(6). Published Online 7 November 2016. DOI: 10.1111/jcom.12258 
claimed in the 'humanitarian technologies' discourses (UN OCHA, 2012; WDR, 2013).

Crucially, the above quotes suggest that the real audience for SMS feedback are the donors who have also pushed for greater accountability as evidence for where their funds are spent. In the humanitarian sector this is often referred to as 'upwards accountability' which, as already explained, is different from accountability to affected people. Aid agencies are dependent on external funding and funders demand evidence of impact which the agencies need to submit so they can continue have access to funds. The short cycle of humanitarian funding heightens the pressure to collect impact evidence. As a result we see that digitized feedback is increasingly prepared and used as evidence for funders instead of being fed back into the affected communities. Although AAP is different from donor accountability, that it is often reduced to metrics captured digitally suggests that donor accountability trumps AAP. Some of these observations confirm findings from earlier emergencies (Krause, 2014) while there are parallels with the critiques around participation in development. Our contribution here is to show that communication technologies become constitutive in shifting accountability from beneficiaries to donors. The irony is that the technological means that were assumed to support greater participation and the democratization of humanitarianism become the tools for disconnection.

It is important to recognize that several humanitarian workers we interviewed were very self-reflexive and aware of the limits of accountability and whom it was for. The Haiyan response inter-agency coordinator expressed these concerns when she wrote that 'the tools and mechanisms [of accountability] have increasingly become an end in themselves' (Wigley, 2015, p. 14). One of our participants echoes these thoughts whilst recognizing the role of donors:

There is a huge, huge push right now in the NGO world to do accountability. It drives me nuts, to be honest, because every single person that I spoke to said "Wow, you've got this great, new technology where people can talk to us. Let's use it for feedback and accountability." [...] So, there's this huge buzzword, "Accountability." And all the donors 
are talking about accountability. [...] Accountability may look great for donors, but needs assessment is how you help people and save lives.

The degree to which communication technology is considered as synonymous with accountability structures is evident in this final observation from our fieldwork where even the smaller agencies with limited resources were compelled to set up SMS hotlines. One of the smallest agencies had their SMS hotline supervised by their director, who was clearly overcommitted with little time to process feedback messages. If having an SMS hotline is almost obligatory, regardless of its usefulness in strengthening accountability to affected people, then we can even consider whether technologized feedback legitimates humanitarian projects rather than democratizes humanitarian action.

\section{Conclusion}

The recovery from Typhoon Haiyan was popularly seen as the ideal laboratory to pilot AAP programmes. This was largely due to the existing communications infrastructure in the Philippines. Several initiatives were rolled out, some including a combination of AAP and CwC efforts for the first time in the history of disaster recovery. Haiyan confirmed that accountability to affected people is integral to the humanitarian agenda. Drawing on a 10-month ethnography and 139 interviews our article compared the perspective of affected people with that of humanitarian workers. In so doing we weighed the enthusiasm surrounding digital technologies for accountability against actual evidence.

Our findings reveal that accountability was narrowly interpreted as feedback confirming earlier studies (Krause, 2014). What counted as feedback was also narrowly defined: usually this involved comments received through the official channels which responded to existing 
programmes. Of all official feedback mechanisms SMS hotlines were clearly prioritized:

feedback received via SMS was more likely to be included in the agency logs and reports. A number of problems ensue from these observations. The narrow definition of feedback misses out the expression of wider concerns relating to people's unmet needs, or their grievances about the government and local patronage which are often expressed outside the designated feedback channels, including in local media such as radio and social network sites such as Facebook. The disaggregation between feedback to agencies and complaints about the local government can be artificial, as aid was typically filtered through existing local government structures. Prioritizing feedback from only one platform (SMS) ignores people's complex communication ecology which is essential once we recognize that accountability is about communication. It is indicative that although affected people expressed a preference for face-to-face interactions with humanitarian workers, most feedback was logged electronically via SMS hotlines while agencies prioritized the setting up of 'hotlines'. We also question whether complex concerns about the recovery can be expressed in the 160 characters allowed in an SMS. Texting tends to reduce complex problems to their barest or most instrumental forms.

What emerged clearly from our data was a reluctance by affected people to offer feedback in the first place. Humanitarian aid was understood within local norms of debt of gratitude that prevent the expression of criticism to one's benefactor. This supplements other forms of silencing, ranging from fears about the withdrawal of aid to lack of confidence, that prevented affected people from voicing their concerns (Madianou, Longboan \& Ong, 2015). These reasons partly explain the low take up of feedback platforms which were only used by a fraction of our participants. Those who offered feedback at best received a small correction to their problem. The alternative was a simple acknowledgement that the message had been logged, 
but with no further follow up while some participants didn't even receive an acknowledgment.

Not closing the feedback loop has important consequences as it can disenfranchise and demoralize those in need - and indeed it was the poorest amongst our participants who never got a response for their complaint. We thus identify a disconnect between affected people and humanitarian agencies. The paradox is that this disconnect is produced through the methods designed to close the bridge and make agencies more accountable to their beneficiaries.

These observations raise the question: if accountability programmes do not serve affected people then who is this feedback for? Our findings suggest that AAP is often reduced to metrics that serve the purpose of upward accountability. In other words, what appears to be accountability to affected people is ultimately accountability to donors who increasingly demand evidence for their funding. This process is heightened by the technologized nature of feedback in the form of SMS, which are easily aggregated into spreadsheets through the use of software such as FrontlineSMS and then forwarded to donors as impact evidence. As the political economy of humanitarian funding illustrates, governments have withdrawn from service provision but remain key as the main NGO funders. The short cycle of humanitarian project funding demands the constant production of reports which are used to justify the continuation of relief projects.

Our argument has foregrounded the role of communication in humanitarian accountability. We developed an analytical framework in order to understand mediated communication, which is essential given the increasing prevalence of digital technologies in humanitarian action. Through our sociotechnical approach we examined both the affordances of digital media platforms and their actual applications and uses in a specific sociopolitical context. Our analysis revealed that affordances, such as interactivity and reach, do not translate into participation. Institutional factors, including the structure of humanitarian funding and the role of 
donors, prevent accountability from reaching its radical promise of correcting asymmetrical power relationships. Although our study is the first to examine the intersection of humanitarian accountability and communication we recognize the parallels with participatory communication which has also been hindered by institutional constraints within development (Waisbord, 2008). Our most original contribution is the argument that technologically mediated communication is a constitutive factor that hinders the realization of humanitarian accountability. Our analysis traced the role of communication technologies in shifting accountability from affected people to donors. The intersection of mobile technology and open source software, such as FrontlineSMS, emerged as having distorting effects for the processes of accountability. The first distortion is that feedback captured via SMS is more likely to be counted as feedback at the expense of other more informal methods. Second, SMS feedback privileges certain kinds of responses (those that can be summarized in 160 characters) compared to more complex or nuanced concerns. Thirdly, the convergence between mobile phones and software streamlines feedback and packages it into databases which provide tangible evidence about the impact of relief programmes. This last feature of technologized feedback is particularly well suited to meet the donors' demand for evidence of impact. Agencies have for a long time juggled the competing demands for 'downwards' and 'upwards' accountability, but the improvement in metrics contributes to the shifting of balance towards a culture of audit rather than a culture of listening. That these shifts take place in the name of greater accountability means that the continuing power imbalance is cloaked under the promise of digital efficiency and transparency.

All this suggests that despite the noble intentions, the intensification of feedback mechanisms and metrics due to digital developments do not necessarily improve humanitarian action nor do they make humanitarian organizations more accountable to beneficiaries. The irony 
here is that the technological platforms identified as solutions by humanitarian agencies ultimately contribute to the disconnect between agencies and local people. What we have is an appearance of accountability which ultimately legitimates the cycle of humanitarian projects. We do however recognize that this is not the result of some inherent technological feature, but the outcome of a particular application of technology in a specific local context and within the wider political economy of humanitarianism. As always, technology can only reveal or amplify the social and political structures already in place and structural changes would need to be made in order for more accountability - instead of audit - to take place. 


\section{References}

Adams, V. (2013). Markets of sorrow, labors of faith. Durham, NC: Duke University Press.

Baron, N. (2010). Always on: language in an online and mobile world. Oxford, UK: Oxford University Press.

Baym, N. (2015). Personal connections in the digital age ( $2^{\text {nd }}$ ed.). Cambridge, UK: Polity. boyd, d. (2014). It's complicated: the social lives of networked teens. Yale, NH: Yale University Press.

Buchanan-Smith, M. (2003). How the Sphere Project came into being. London: Overseas Development Institute. Retrieved 7 February 2016 from http://www.odi.org/sites/odi.org.uk/files/odi-assets/publications-opinion-files/176.pdf

Buchanan-Smith, M., Ong, J., \& Routley, S. (2015). Who's Listening? Accountability to Affected People in the Haiyan Response. London, UK: Plan International. Retrieved 7 February 2016 from http://www.alnap.org/resource/20631

Castells, M., Fernandez-Ardevol, M., Qiu, J. \& Sey, A. (2007). Mobile communication and society: a global perspective. Cambridge, MA: MIT Press.

Cooke, B., \& Khothari, U. (Eds.). (2001). Participation: The new tyranny? London: Zed Books. Communicating with Disaster Affected Communities Network [CDAC] (2014). The CDAC network: Typhoon Haiyan learning review. Retrieved 7 February 2016 from http://www.cdacnetwork.org/contentAsset/raw- data/7825ae17-8f9b-4a05-bfbd7eb9da6ea $8 \mathrm{c} 1 /$ attachedFile2

Crawford, K., \& Finn, M. (2015). The limits of crisis data: analytical and ethical challenges of using social and mobile data to understand disasters. GeoJournal, 80(4), 491-502 
Darcy, J., Alexander, J., \& Kiani, M. (2013). Humanitarian Accountability Report. Geneva:

Humanitarian Accountability Partnership. Retrieved 7 February 2016 from

http://www.hapinternational.org/pool/files/2013-har.pdf

Davis, A. (2007). Concerning accountability of humanitarian action. Humanitarian Practice

Network, 58. London: Overseas Development Institute. Retrieved 7 February 2016

http://odihpn.org/wp-content/uploads/2007/04/networkpaper058.pdf

de Waal, A. (1997). Famine crimes: politics and the disaster relief industry in Africa. London:

James Currey Publishers.

Groupe Special Mobile Association [GSMA] (2014) Country overview: Philippines. Growth through innovation. Retrieved 7 February 2016 from

https://gsmaintelligence.com/research/?file=141201-philippines.pdf\&download

Humanitarian Accountability Partnership [HAP] (2010). The 2010 HAP Standard in

accountability and quality management. Geneva: HAP International.

Hartmann, C., Rhoades, A., \& Santo, J. (2014). Starting the conversation. Information, feedback and accountability through communications with communities in post-Typhoon Philippines.

Geneva: International Organization for Migration (IOM).

IRIN (2014) Where is all the money going? The Humanitarian Economy. Retrieved 14

Septemeber 2016 from: http://newirin.irinnews.org/the-humanitarian-economy

Jacobs, A. (2015a). Pamati Kita: let's listen together. Humanitarian Exchange, 23, 16-18.

Jacobs, A. (2015b). Enhancing Community Engagement during Humanitarian Response.

Proposition Paper for the World Humanitarian Summit. Retrieved from

http://www.alnap.org/resource/20282

Jean, I., with Bonino, F. (2014). Investing in listening. ALNAP/CDA Case Study. London, UK: 


\section{ODI/ALNAP.}

Krause, M. (2014). The good project. Chicago, IL: Chicago University Press.

Lau, A.L \& Cornelio, J. (2015). Tzu Chi and the philanthropy of Filipino volunteers. Asian Journal of Social Science, 43(4), 376-399.

Leal, P. (2007). Participation: the ascendancy of a buzzword in the neoliberal era. Development in Practice, 8, 1-26.

Ling, R., \& Donner, J. (2009). Mobile Communication. Cambridge, UK: Polity.

MacKenzie, D., \& Wajcman, J. (1999). The social shaping of technology. Buckingham, UK: Open University Press.

McKay, D. (2012). Global Filipinos. Bloomington, IN: Indiana University Press.

Madianou, M. (2015). Digital inequalities and second-order disasters: social media in the Typhoon Haiyan recovery. Social Media and Society, 1(2), 1-11, doi: $10.1177 / 2056305115603386$

Madianou, M., Longboan, L., \& Ong, J.C. (2015). Finding a voice through humanitarian technologies? Communication technologies and participation in disaster recovery. International Journal of Communication, 9(1-19) 1932-8036/20150005

Madianou, M., \& Miller, D. (2012). Migration and new media: Transnational families and polymedia. London, UK: Routledge.

Manyozo, L. (2012). Media, Communication and Development. New Delhi and London: Sage.

O’Neill, O. (2002). A Question of Trust. Cambridge, UK: Cambridge University Press.

Ong, J.C., Flores, J. \& Combinido, P. (2005). Obliged to be grateful. London, UK: Plan

International. Retrieved 23 February 2016 from http://www.alnap.org/resource/20633.

National Economic and Development Authority. (2013). Reconstruction assistance on Yolanda 
(Government Report). Pasig, Philippines: National Economic and Development Authority. Available from http://www.neda.gov.ph

Palen, L. (2008). Online social media in crisis events. EDUCAUSE Quarterly, 31(3).

Pertierra, R., Ugarte, E., Pingol, A. \& Decanay, N. (2002) Txting selves: cellphones and Philippine modernity. Manila, Philippines: De La Salle University Press.

Power, M. (1997). The audit society: rituals of verification. Oxford, UK: Oxford University Press.

Rafael, V. (1990). Patronage and pornography: Ideology and spectatorship in the Marcos years. Comparative Studies in Society and History, 32, 282-304.

Rieff, D. (2002). A bed for the night: humanitarianism in crisis. London, UK: Vintage.

Steering Committee for Humanitarian Response SCHR (2010). SCHR peer review on accountability to disaster-affected populations: an overview of lessons learned. Geneva, Switzerland: IFRC. Retrieved 23 February 2016 from http://www.alnap.org/resource/5797

Stein, J. G. (2008). Humanitarian organisations: accountable - why, to whom, for what, and how? In Barnett, M., \& Weiss, T. (Eds.), Humanitarianism in question: politics, power, ethics (pp. 124-143). Ithaca, NY: Cornell University Press.

Strathern, M. (2000). Audit cultures. London, UK: Routledge

Taylor, G., Stoddard, A., Harmer, A., Haver, K., \& Harvey, P. (2012) The state of the humanitarian system. London: ALNAP. $\quad$ Retrieved 7 February 2016 http://www.alnap.org/resource/6565

Terry, F. (2002). Condemned to repeat? The paradox of humanitarian action. Ithaca, NY: Cornell University Press. 
United Nations Office for the Coordination of Humanitarian Affairs [UNOCHA] (2013) Humanitarianism in the Network Age. OCHA policy and studies series. New York: OCHA

Waisbord, S. (2008). The institutional challenges of participatory communication in international aid. Social Identitites, 14(4), 505-522.

Wigley, B. (2015). Constructing a culture of accountability: lessons from the Philippines. Humanitarian Exchange, 23, 13-16.

World Bank (2012). Maximizing mobile: information and communications for development. Washington, DC: The World Bank. Retrieved 7 February 2016, http://siteresources.worldbank.org/EXTINFORMATIONANDCOMMUNICATIONANDTE

\section{CHNOLOGIES/Resources/IC4D-2012-Report.pdf}

Wilkins, K. G. (Ed.). (2000) Redeveloping communication for social change: theory, practice and power. Lanham, MD: Rowman and Littlefield.

World Disasters Report [WDR] (2013). Technology and the future of humanitarian action. Geneva: International Federation of Red Cross and Red Crescent Societies.

Notes

\footnotetext{
${ }^{1}$ Although many agencies subscribed to Sphere and HAP, the reform initiatives haven't been uncontested - Medicins Sans Frontiers (MSF) for instance, has not signed either in line with their position that foregrounds autonomy. Agencies with a medical background (such as MSF) are not preoccupied with accountability or beneficiary participation as that is not a traditional concern in medicine.

${ }^{2}$ Except for Tacloban, all the names of places and all informants have been anonymized as part of our research ethics protocol.

Madianou, M., Ong, J., Longboan, L. and Cornelio, J. (2016) The appearance of accountability: communication technologies and power asymmetries in humanitarian aid and disaster recovery. Journal of Communication vol, 66(6). Published Online 7 November 2016. DOI: 10.1111/jcom.12258
} 
${ }^{3}$ All participants were guaranteed anonymity while our research was informed by the principles of the ESRC's Framework for Research Ethics (http://www.esrc.ac.uk/funding/guidance-forapplicants/research-ethics/)

${ }^{4}$ International NGOs channeled aid via the local administrative units, for example the local barangay [neighbourhood] elected leader.

5 The modest changes in the form of 'tweaks' to existing programmes facilitated by accountability officers and their teams have been identified by the sector as an improvement compared to practices in previous humanitarian emergencies (Buchanan-Smith, Ong \& Routley 2015). 